Gut, 1960, 1, 175.

\title{
USE OF BISACODYL IN PREPARATION OF THE BOWELS FOR A BARIUM ENEMA
}

BY

\section{J. G. SOWERBUTTS}

From the Radiodiagnostic Department, the London Hospital

This account of a new and successful technique in preparing patients for a barium enema examination will interest clinicians, for its eventual adoption by radiologists would greatly reduce the discomfort of this invaluable but disagreeable investigation.

Half a century has elapsed since Rieder (1904) and Schüle (1904) first reported the use of opaque media for radiographic examination of the colon, during which time many other techniques have been improved. At the same time, whether due to medical prejudice or to the assertion of an exclusive nursing prerogative over the patient's bowels, methods of preparing the colon for the injection of barium do not appear to have shared in this process of general refinement. Nevertheless, a useful outcome from barium enema examination depends in no small measure upon this neglected aspect of technique.

Haenisch (1911) gave the first full review of the subject, and his exhaustive account includes the statement that "thorough cleansing of the intestine by giving purgatives and cleansing enemata is highly essential". Methods in general would appear to have changed little since his day. Various authorities (Sante, 1956; Storch, 1957) recommend a variety of measures, starting with dietary restriction of considerable austerity, and leading, via purgation with castor oil or phenolphthalein, to the administration of enemata of normal saline, soap and water, or, where gas is excessive, of ox bile and turpentine. Alternatively, plain water washouts may be given at half-hourly intervals until the fluid is returned clean. According to a standard British textbook (Shanks, 1958), the only satisfactory method of giving it is by means of the Studa chair in which 30-50 pints of fluid may have to be used before the return is clear.

Because the absence of an agreed standardized procedure makes it impossible to generalize, it is probable that the practice in most radiodiagnostic departments in this country closely resembles our own in relying largely on enemas and colonic lavage.

It was not until 1953 that a practical alternative to these methods became available. In that year the German pharmacologist Schmidt (1953) reported the synthesis of a new laxative substance now known as bisacodyl ("dulcolax"). This substance is not absorbed from the gut and is strikingly free from toxicity. Its presence within the lumen of the bowel initiates normal peristalsis due to direct contact with the mucosa, acting possibly through the local nerve plexuses. Clinical reports from Germany (Stockmeier, 1953; Frankl, 1953) confirmed its effectiveness in a variety of forms of constipation, and, since its widespread adoption in Britain, reports have appeared of its use in general medical and surgical cases (Church, 1959; Rutter, 1959) and in chronic sick and geriatric patients (Clark, 1957).

As a method of preparation for radiography, "dulcolax" suppositories were used by Hauff (1954) and Kolshorn (1954). The procedure used by these investigators consisted of either "dulcolax" tablets or a suppository on the evening before examination, and one suppository on the morning of examination, satisfactory bowel clearances being reported. Keogh and Fraser (1958) compared the effectiveness of bowel preparation in 100 patients prepared with castor oil and a cleansing enema and 142 patients given "dulcolax", and found that the "dulcolax" series gave better results. Good results were also obtained in a larger series of 249 patients prepared with bisacodyl (Poppel and Bangappa, 1959).

\section{Method OF INVESTIGATION}

In order to establish that it was possible to dispense with the enema and lavage commonly used in preparation for the barium enema, a "blind" enquiry was started in 
this hospital in which the radiologists had to report on the adequacy of preparation at the time they read the films, without knowing what form of preparation had been used.

With the consent and cooperation of a number of medical and surgical consultants, patients referred for barium enema examination were allocated either to "old" or to "new" groups. Patients were allocated largely on the basis of the referring consultant, the ward sister being told that Mr. A's patients were to be given the "old" preparation and Dr. B's the "new", the method being such that no observable difference emerged in age, nature or severity of illness, etc., between the two groups of cases.

\section{“OLD” METHOD OF PREPARATION}

\begin{tabular}{llll}
\hline Previous evening $\quad \ldots$ & $\ldots$ & $\begin{array}{l}\text { One-and-a-half pint enema (4 oz. soft } \\
\text { soap per pint) or disposable enema } \\
4 \text { to } 6 \mathrm{hr} \text {. before examination } \\
\text { Plain water lavage until clear }\end{array}$ \\
\hline
\end{tabular}

\begin{tabular}{l} 
"NEW" METHOD \\
\hline $\begin{array}{l}\text { Previous evening . . } \\
6 \text { a.m. to } 7 \text { a.m. on morning }\end{array}$ \\
$\begin{array}{l}\text { before examination } \\
\text { One hour before examination }\end{array}$ \\
$\begin{array}{l}\text { One "dulcolax", } 10 \text { mg. (2 tabs.) by mouth } \\
\text { One "dulcolax" suppository }\end{array}$ \\
\hline
\end{tabular}

As a rule the examination took place either at 11 a.m. or 1.30 p.m.

A note of the method used was made by the ward sister but did not appear on the form requesting a barium enema. When he had read the films the radiologist concerned was asked to complete a pro-forma stating whether preparation was "satisfactory" or "unsatisfactory", and, if the latter, for what reason and whether a diagnosis was still possible. The criteria used were as follows:-

\section{Unsatisfactory}

Faecal matter present in gross amount throughout colon, or failure to retain the enema

\section{Satisfactory}

Either empty of faeces, or faeces present in small amount insufficient to interfere with making a diagnosis

I was aware of the preparation used in each case but was not concerned with giving the initial opinion on the films. When the examination was over, the method of preparation used was entered on a pro-forma.

Two hundred cases were reviewed in this manner, 100 being given the "old" preparation and 100 the "new". The patients, who were all in-patients, included both sexes and all ages from 10 to 82 years. The majority were under investigation for suspected neoplasm or inflammatory lesions of the large bowel. Results are given in the accompanying table. Analysis showed that unsatisfactory results by either method bore no relation to age, sex, or to the ward which was preparing the enema. The patients marked "satisfactory" were later graded into "good" where there was no faecal residue at all in the colon, and "satisfactory" where minimal faecal matter was present in one segment of the colon only.

Side-effects in the "dulcolax" series were never serious but an occasional patient complained of colicky pain,
TABLE

RESULTS USING DIFFERENT METHODS OF PREPARATION FOR BARIUM ENEMA

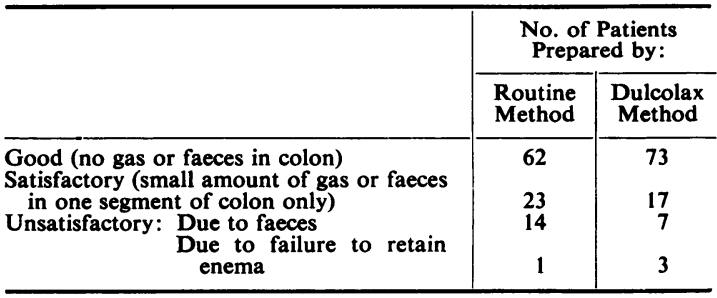

*Since each group contained 100 patients, the figures may be read as percentages.

nausea, or a burning sensation in the rectum after the suppository had been inserted. Our experience is that two tablets give an adequate result and a higher dose is inadvisable, particularly in the older age groups.

The relative lack of side-effects and the ease with which "dulcolax" is given make this preparation very suitable for the out-patient barium enema examination. Since the present series was completed many patients having a barium enema have been satisfactorily examined in this way.

\section{Discussion}

The use of enemata and colonic lavage as a means of preparation for barium enema carries with it a number of disadvantages. In a proportion of cases the colon is not cleared or only partly so and residual gas or faeces may be troublesome. If the procedure is not carried out a sufficient length of time before the examination, droplets of fluid remaining in the colon may obscure the mucosal pattern, or the bowel may be irritated by the agents employed. A further important drawback is the risk of water intoxication to which attention has recently been drawn (Lancet, 1959). It is known that in susceptible cases absorption of hypotonic fluid can lead to neurological disturbances (Hiatt, 1951). Although most reported instances are in cases of megacolon, Ziskind and Gellis (1958) have shown that even in cases with a normal colon the volume of fluid returned after colonic lavage amounts to only 10 to $50 \%$ of that injected. When it is remembered that the procedure may involve the injection and return of 20 to 30 pints of water over the course of several hours, it becomes clear that an element of risk undoubtedly exists. Moreover, when the impact upon the patient, both physically and psychologically, of this "onslaught by water" is taken into account, many would doubt whether it can be justified at all except in the presence of clear and unequivocal indications.

Finally, the time expended by the nursing staff in administering the enema and lavage (at least half an hour), as well as in cleaning and maintaining the 
equipment, makes the search for an alternative procedure an overdue medical obligation.

\section{CONCLUSION}

The features of the ideal method of bowel preparation may be enumerated as follows:-

(1) It should produce complete and consistent bowel emptying within a predictable period of time.

(2) After emptying, the bowel should be left in an otherwise unaltered condition.

(3) From the patients' point of view the period of preparation should be short and the method should cause neither discomfort nor apprehension.

(4) From the nurses' point of view the method should be simple and quick.

(5) From the radiologists' point of view the procedure should result in a clear, unobstructed field of vision.

(6) There should be no side-effects or complications.

The conclusion to be drawn from this enquiry is that bisacodyl is an effective substitute for traditional methods of preparing the bowel and has the additional advantages of being simpler and quicker to administer and of being less unpleasant for the patient.

In view of the increasing use in hospitals of disposable enemata, it may be of interest to mention the following relative costs:-

\begin{tabular}{l|l}
\hline & Basic Cost to N.H.S. \\
$\begin{array}{l}\text { Disposal enema } \\
\text { Dulcolax régime (2 tabs. + 2 suppositories) }\end{array}$ & $1 s .8 d$. \\
\hline
\end{tabular}

My thanks are due to Dr. L. J. Rae, Director of the Radiodiagnostic Department, for his help and advice, and to the registrars, radiographers, and staff who have cooperated in this project.

I also acknowledge with thanks the assistance of the Medical Department of the Boehringer Division of Pfizer's Limited who supplied the original samples of "dulcolax" and obtained for me translations of some of the German literature.

\section{REFERENCES}

Church, G. (1959). Scot. med. J., 4, 94

Clark, A. N. G. (1957). Brit. med. J., 2, 866.

Frankl, R. (1953). Medizinische, p. 1587.

Haenisch, G. F. (1911). Münch. med. Wschr., 58, 2375.

Haenisch, G. F. (1911). Münch. med. Wschr.,

Hiatt, R. B. (1951). Ann. Surg., 133, 313.

Keogh, R. K., and Fraser, R. G. (1958). J. Canad. Ass. Radiol., 9, 66.

Kolshorn, R. (1954). Münch. med. Wschr., 96, 949.

Lancet (1959). "Gastrointestinal Haemorrhage", 1, 559.

Poppel, M. H., and Bangappa, C. K. (1959). Amer. J. Roentgenol., 81, 696.

Rieder, H. (1904). Münch. med. Wschr., 51, 1548.

Rutter, A. G. (1959). Lancet, 1, 1173.

Sante, L. R. (1956). A Manual of Roentgenological Technique, 18th ed., p. 239. Edwards, Ann Arbor, Michigan.

Schmidt, L. (1953). Arzneimittel-Forsch., 3, 19.

Schüle (1904). Arch. Verdau.-Kr., 10, 111.

Shanks, S. C. (1958). In A Textbook of X-ray Diagnosis by British Authors, ed. S. C. Shanks and P. Kerley, vol. III., p. 355. Authors,

Stockmeier, F. (1953). Münch. med. Wschr., 95, 1058

Storch, C. B. (1957). Fundamentals of Clinical Fluoroscopy, 2nd ed., p. 234. Grune and Stratton, New York.

Ziskind, A., and Gellis, S. S. (1958). A.M.A. Amer. J. Dis. Child. 96, 699.

*In receipt of a Medical Research Council grant. 